\section{Annealing Behaviour of Recoil Cobalt-57 Atoms in Hexammine Nickel Chloride}

RECOIL chemistry of ${ }^{57} \mathrm{Co}$ (half-life: 270 days) produced by the $(\gamma, p)$ reaction or by the decay processes $\left(\beta^{+}\right.$and $E C$ ) in hexammine nickel chloride has not been studied so far. In this work, studying behaviour of recoil ${ }^{57} \mathrm{Co}$ atoms in the nickel complex on thermal annealing, I have found remarkable difference between annealing reactions of ${ }^{57} \mathrm{Co}$ atoms produced by the ${ }^{58} \mathrm{Ni}(\gamma, p)^{57} \mathrm{Co}$ reaction and those of ${ }^{57} \mathrm{Co}$ produced by the decay processes of ${ }^{57} \mathrm{Ni}$.

Hexammine nickel chloride $\mathrm{Ni}\left(\mathrm{NH}_{3}\right)_{6} \mathrm{Cl}_{2}$ was prepared by the orthodox method and recrystallized in concentrated ammonia'. $\mathrm{Ni}\left(\mathrm{NH}_{3}\right)_{6} \mathrm{Cl}_{2}$ labelled with ${ }^{57} \mathrm{Ni}$ (halflife: $36 \mathrm{~h}$ ) was prepared in the same way as aforementioned starting from metallic nickel powder irradiated by $\gamma$-rays of $20 \mathrm{MeV}$. $\gamma$-Rays were generated by an electron linear accelerator (maximum energy : $20 \mathrm{MeV}$, mean beam current: $30 \mu \mathrm{amp})$. The target material was irradiated while being cooled by dry ice. Radiation decomposition was minimized by cooling (< about 1 per cent). Chemical forms of ${ }^{57} \mathrm{Co}$ were analysed by a cation exchanger column ('Diaion $S K$ 1', 100-200 mesh, $1 \mathrm{~cm} \times 7 \mathrm{~cm}$ ), after dissolving the irradiated complex in $0 \cdot 1 \mathrm{~N}$ hydrochloric acid. The $\mathrm{Co}^{2+}$ fraction was further separated from $\mathrm{Ni}^{2+}$ or $\mathrm{Ni}\left(\mathrm{NH}_{3}\right)_{6}{ }^{2+}$ using an anion exchange column ('Diaion $S A \quad 100^{\prime}, 100-200$ mesh, $1 \mathrm{~cm} \times 3 \mathrm{~cm}$ ) under strongly acid condition ( $>8 \mathrm{~N} \mathrm{HCl}$ ). By these procedures principal chemical forms of ${ }^{57} \mathrm{Co}$ could be separated satisfactorily ${ }^{2}$. Radioactivity of ${ }^{57} \mathrm{Co}$ samples was measured by a 20 channel $\gamma$-ray spectrometer of the Baird-Atomic Instrument Co.

The distribution of recoil species thus analysed is listed in Table 1. In the case of the $(\gamma, p)$ reaction, $\mathrm{Co}^{2+}$ (or its precursor) changes into $\mathrm{Co}\left(\mathrm{NH}_{3}\right)_{5} \mathrm{Cl}^{2+}$ and $\mathrm{Co}\left(\mathrm{NH}_{3}\right)_{6}{ }^{3+}$ on thermal annealing at $87^{\circ} \mathrm{C}$. Especially increase of the $\mathrm{Co}\left(\mathrm{NH}_{3}\right)_{5} \mathrm{Cl}^{2+}$ fraction is the main event in this case. On the decay processes, however, the main event on thermal annealing is increase of $\mathrm{Co}\left(\mathrm{NH}_{3}\right)_{6}{ }^{3+}$, which corresponds to the decrease of $\mathrm{Co}^{2+}$ (or its precursor). For the samples standing at room temperature, distribution of recoil products shows similar tendency to the annealed one.

These phenomena seem to be very important in interpreting annealing behaviour of recoil cobalt atoms because ${ }^{57} \mathrm{Co}$ recoil chemistry in nickel complexes eliminates possibilities of guided reactions to the parent species which are usually observed in ${ }^{60} \mathrm{Co}$ recoil atoms produced by the $(n, \gamma)$ reaction. In this sense, annealing of ${ }^{57} \mathrm{Co}$ atoms is free from guiding to the parent species in the damaged zone in the crystal.

The reason why increase of $\mathrm{Co}\left(\mathrm{NH}_{3}\right)_{5} \mathrm{Cl}^{2+}$ is the main event on annealing of ${ }^{57} \mathrm{Co}$ atoms produced by the $(\gamma, p)$ reaction will be understood by considering a fairly large fragmentation zone around the ${ }^{57} \mathrm{Co}$ recoil atoms (maximim recoil energy: $\sim 0.2 \mathrm{MeV}$ ). Annealing reactions here can be interpreted to be of synthetic type among

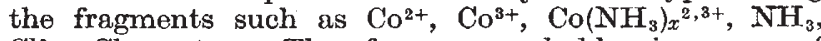
$\mathrm{Cl}^{\circ}, \mathrm{Cl}^{-}$, etc. Therefore, remarkable increase of $\mathrm{Co}\left(\mathrm{NH}_{3}\right)_{5} \mathrm{Cl}^{2+}$ occurs by recombination of fragments.

In the case of ${ }^{57} \mathrm{Co}$ atoms produced by the decay processes fragmentation will be very small, and electronic change around ${ }^{57} \mathrm{Co}$ atoms will be important, because recoil energy of the atoms on the decay processes is small (maximum: $34 \mathrm{eV}$ ), and charge distribution will be created on the decay processes ${ }^{3}$. As in Wertheim's observation $^{4}$, a recoil cobalt atom will finally acquire +2 or +3 valence state in the crystal in very short time after the decay processes. At least some percentage of decayed ${ }^{57} \mathrm{Co}$ will remain in the chemical forms of $\mathrm{Co}\left(\mathrm{NH}_{3}\right)_{6}{ }^{2+}$ or $\mathrm{Co}\left(\mathrm{NH}_{3}\right)_{6}{ }^{3+}$, leaving electronic defects around the decayed atom. Annealing reaction in this region will be mainly of electronic type. For example, $\mathrm{Co}\left(\mathrm{NH}_{3}\right)_{6}{ }^{2+}$ (unstable in an aqueous solution) will be converted into $\mathrm{Co}\left(\mathrm{NH}_{3}\right)_{e}{ }^{3+}$ (stable in an aqueous solution) by giving up one electron to the neighbouring electronic defects. This possibility has already been discussed by Harbottle and myself ${ }^{5,6}$. In Table 1 , increase of $\mathrm{Co}\left(\mathrm{NH}_{3}\right)_{6}{ }^{3+}$ on annealing of decayed ${ }^{57} \mathrm{Co}$ atoms will most probably be interpreted by change of its electronic state. The difference between the main tendencies in annealing behaviour of ${ }^{57} \mathrm{Co}$ produced by the $(\gamma, p)$ reaction and that of the decayed atom will be a good indication of two types of annealing reactions : one, a synthetic type, and the other, an electronic type.

I thank Dr. N. Shibata for his discussions, Mr. M. Hara and $\mathrm{Mr}$. H. Nozaki for their assistance.

\section{KENJI Yoshitara}

Japan Atomic Energy Research Institute,

$$
\text { Tokai, Tbaraki, Japan. }
$$

${ }^{1}$ Brauer, G., Handbuch der präparativen anorganischen Chemie, 2, 1344 (Ferdinand Enke Verlag, Stuttgart, 1962).

${ }^{2}$ Ikeda, N., Yoshihara, K., and Yamagishi, S., Bull. Chem. Soc., Japan, 34, 140 (1961).

${ }^{8}$ Snell, A. H., Pleasonton, F., and Carlson, T. A., Chemical Effects of Nuclear Transformations, 1, 147 (IAEA. Vienna, 1961).

'Wertheim, G. K., Kington, W. R., and Herber, R. H., J. Chem. Phys., 37, 687 (1962).

5 Harbottle, G., Chemical Effects of Nuclear Transformations, 1, 301 (IAEA, Vienna, Austria, 1961).

- Yoshihara, K., and Harbottle, G., Radiochem. Acta, 1, 68 (1963).

\section{Jets from Imploding Bubbles}

BowDEN has suggested that micro-Munro jets may play a part in the initiation of non-homogeneous explosive systems ${ }^{1}$. In addition, he and Brunton have shown that such jets can be formed by impacting a vessel containing a liquid with a hemispheric cavity located on its surface ${ }^{2}$. In an investigation of possible mechanisms for the initiation and propagation of low-velocity detonations in a cavitated liquid explosive, we have investigated the formation and subsequent behaviour of jets from bubbles in water and nitroglycerin-ethylene glycol dinitrate (NG-EGDN)

In theso experiments, roughly hemispherical cavities were formed on the surface of the liquid under an overlay of vinylidene chloride film having a thickness of 0.0006 in. The cavities were then collapsed by a shock wave derived from a tetryl donor and attenuatcd by an aluminium plate $0.75 \mathrm{in.} \mathrm{thick.}$

Selectcd views from a framing camera sequence showing water micro-jets are presented in Fig. 1. In this trial, a 1-in. diameter $\times 1$-in. long tetryl donor was used; the depth of water, contained in a transparent tank with the attonuator serving as a base, was 1 in. In frame 2 of the sequence, a hemispherical shock wave can be seen approach. ing the four bubbles in the left side of the container. The

Table 1. Drstribution of ReCOII ${ }^{52} \mathrm{CO}$ AtOMs IN $\mathrm{Ni}\left(\mathrm{NH}_{3}\right)_{6} \mathrm{Cl}_{8}$

\begin{tabular}{|c|c|c|c|c|c|c|}
\hline Process & Irradiation & Storage & Annealing & $\mathrm{Co}^{2+}$ & $\mathrm{Co}\left(\mathrm{NH}_{3}\right)_{5} \mathrm{Cl}^{2+}$ & $\mathrm{Co}\left(\mathrm{NH}_{3}\right)_{6}{ }^{3+}$ \\
\hline$\beta^{+}$and $E C$ & $-79^{\circ} \mathrm{C} 30 \mathrm{~min}$ & $\begin{array}{lr}-79^{\circ} \mathrm{C} & 15 \mathrm{~min} \\
-79^{\circ} \mathrm{C} & 15 \mathrm{~min} \\
-79^{\circ} \mathrm{C} & 24 \mathrm{~h}^{*} \\
-79^{\circ} \mathrm{C} & 95 \text { days } \\
-79^{\circ} \mathrm{C} & 20 \text { days } \\
-79^{\circ} \mathrm{C} & 21 \text { days } \\
\text { Room temperature }\end{array}$ & 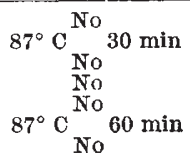 & $\begin{array}{l}82 \pm 2 \% \\
54 \pm 2 \\
78 \pm 2 \\
82 \pm 2 \\
66 \pm 2 \\
52 \pm 2 \\
44 \pm 1\end{array}$ & $\begin{array}{l}4 \cdot 4 \pm 0 \cdot 4 \% \\
24 \pm 1 \\
3 \cdot 7 \pm 0 \cdot 4 \\
3 \cdot 3 \pm 0 \cdot 3 \\
1 \cdot 6 \pm 0 \cdot 1 \\
1 \cdot 2 \pm 0 \cdot 1 \\
1 \cdot 6 \pm 0 \cdot 1\end{array}$ & $\begin{array}{l}14 \pm 1 \% \\
22 \pm 1 \\
18 \pm 1 \\
15 \pm 1 \\
32 \pm 1 \\
45 \pm 1 \\
51 \pm 2\end{array}$ \\
\hline
\end{tabular}

* Additional effects of the decay processes of ${ }^{57} \mathrm{Ni}$ (half-life: $36 \mathrm{~h}$ ) produced by the $(\gamma, n)$ reaction should be considered. However, the effects are small within $1 \mathrm{~h}$ after irradiation. 